\title{
Being Disconnected from Life- Meanings of Existential Loneliness as Narrated by Frail Older People
}

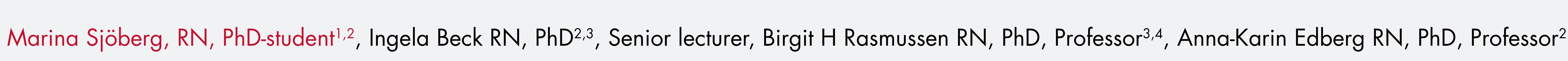

The Faculy of Health and Society, Department of Care Science, Malmö University, Malmö, Sweden 2Department of Health and Sociely, Kristianstad University, Kristianstad, Sweden 3The Facully of Medicine, Department for Health Sciences, Lund University, Lund, Sweden

O- -

\section{BACKGROUND}

Existential loneliness, a deeper sense of loneliness, seems to occur in relation to loss of bodily functions but also losses of significant others who pass away. Talking others about existential issues is important but difficult for health professionals as well as tor the older people themsel ves. Knowledge aboul older people's experiences of professionals.

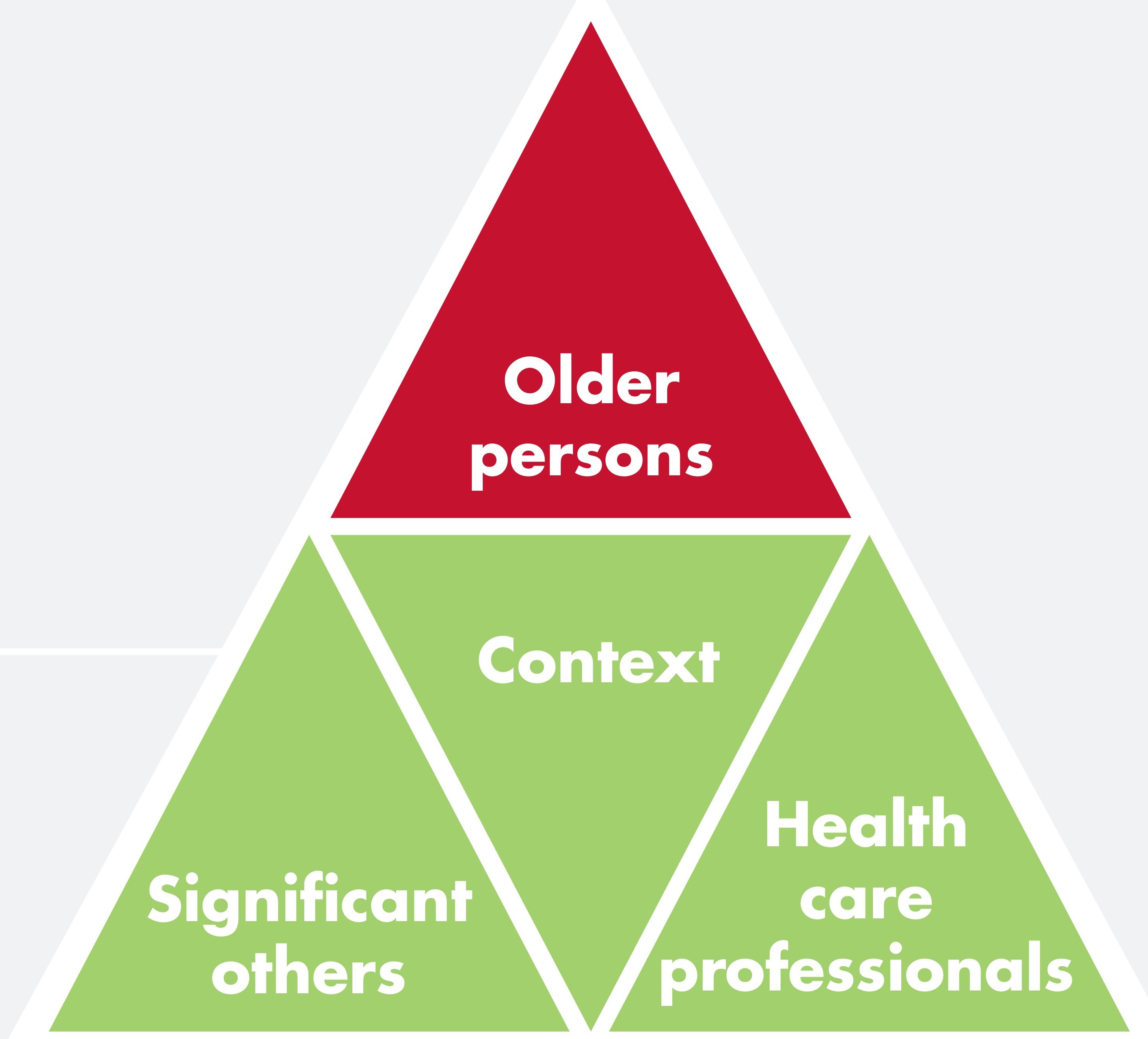

The LONE study

This study is part of a larger research project, the LONE study, where existential oneliness is explored through interviews with older persons, their signiticant others and
health care professionals. The LONE study is in the development phase of designing complex intervention.
AIM

To illuminate meanings of existential loneliness as narrated by frail old people

METHODS

- Individual interviews

Phenomenological hermeneutical analysis

\section{SAMPLE}

Characteristics

Men/women

Age, median (range)

$12 / 11$

Widowers/Widows

Single households/Cohabiting

$85(76-101)$

(angle households

Outpatient Primary Care Center

Homecare

Residential care

Hospital

Specialized palliative home care

Specialized palliative ward
Comprehensive understanding

'Being disconnected from life'

Findings

- Being trapped in a frail and deteriorating body

- Being met with indifference

- Having nobody to share life with

- Lacking purpose and meaning.

\section{Conclusions}

The threatening of the lived body by illness and physical limitation affects access to the world. Being met with indifference and being unable to share one's triggering an experience of meaninglessness and existential loneliness, i.e, disconnection from life 